\title{
Sexuality and Reproduction in HIV-Positive Women: A Meta-Synthesis
}

\author{
Ewa Carlsson-Lalloo, RN, MHCSci, ${ }^{1,2}$ Marie Rusner, RN, MSc, PhD, ${ }^{1,3}$ \\ Åsa Mellgren, MD, PhD, ${ }^{2,3}$ and Marie Berg, RN, RM, MNSci, MPH, $\mathrm{PhD}^{1,4}$
}

\begin{abstract}
The increased access to effective antiretroviral treatment (ART) has made HIV comparable to a chronic disease in terms of life expectancy. Needs related to sexuality and reproduction are central to overall health and well-being. An interpretative meta-synthesis was performed to synthesize and assess how HIV-positive women's experiences of sexuality and reproduction have been described in qualitative studies. A total of 18 peer-reviewed qualitative studies were included, which comprised a total of $588 \mathrm{HIV}$-positive interviewed women. The studies originated from resource-rich countries outside the Asian and African continents. The analysis, resulting in a lines-ofargument synthesis, shows that HIV infection was a burden in relation to sexuality and reproduction. The weight of the burden could be heavier or lighter. Conditions making the HIV burden heavier were: HIV as a barrier, feelings of fear and loss, whereas motherhood, spiritual beliefs, and supportive relationships made the HIV burden lighter. The findings are important in developing optimal health care by addressing conditions making the burden of HIV infection lighter to bear. In future research there is a need to focus not only on examining how HIV-positive women's sexual and relationships manifest themselves, but also on how health care professionals should provide adequate support to the women in relation to sexuality and reproduction.
\end{abstract}

\section{Introduction}

EXUal AND ReProductive Well-Being is an important part of good health and of life itself, and is an integral part of being human and being a woman. ${ }^{1}$ Many conditions and physiological events in a woman's life may significantly impact on sexuality and reproduction and cause changes and concern, ${ }^{2}$ of which HIV infection is such a condition. ${ }^{3}$

Since HIV was discovered in the early 1980s, the HIV/ AIDS epidemic had spread to approximately 37 million people by the end of $2014^{4}$ and is globally the leading cause of death among women of reproductive age. ${ }^{5}$ As a consequence of the increased access to effective antiretroviral treatment (ART) HIV infection in terms of life-expectancy is being considered as a chronic, rather than a lethal, disease in properly treated persons. ${ }^{6,7}$ Beyond medical care, health care providers therefore have to consider social and psychological needs to help the patients with HIV to better health, ${ }^{8}$ including their sexual and reproductive health.
Girls and women are particularly vulnerable to HIV infection due to a combination of biological factors and genderbased inequalities, particularly in cultures that limit women's knowledge about HIV and their ability to protect themselves and negotiate safer sex. ${ }^{5}$ In many settings, HIV-positive persons are not expected to have a sexual life at all because of the risk of transmission of HIV. ${ }^{9}$ However, a Canadian study shows that the majority of the HIV-infected women are sexually active after diagnosis. ${ }^{10}$ Being an HIV-positive woman makes sexual and reproductive health more complex because of the HIV status and therefore these women have unique challenges such as partner relationships, sexual satisfaction, and child bearing. ${ }^{11,12}$ Accordingly sexual and reproductive health need to be addressed in high quality HIV services that may contribute to increased quality of life and better HIV prevention. ${ }^{3,13}$

Studies examining sexual and reproductive health among HIV-infected persons are mostly quantitative and often focus on HIV prevention, unprotected sexual contacts, and condom

\footnotetext{
${ }^{1}$ Institute of Health and Care Sciences, Sahlgrenska Academy, Gothenburg, Sweden.

${ }^{2}$ Clinic of Infectious Diseases, Södra Älvsborg Hospital, Borås, Sweden.

${ }^{3}$ Department of Research, Södra Älvsborg Hospital, Borås, Sweden.

${ }^{4}$ Centre for Person-Centred Care (GPCC), University of Gothenburg, Gothenburg, Sweden.
}

(C) Ewa Carlsson-Lalloo, et al., 2015; Published by Mary Ann Liebert, Inc. This Open Access article is distributed under the terms of the Creative Commons Attribution Noncommercial License (http://creativecommons.org/licenses/by-nc/4.0/) which permits noncommercial use, distribution, and reproduction in any medium, provided the original author(s) and the source are credited. 
use. Since figures and statistical calculations alone cannot describe the complexity of sexuality and reproduction for HIV-positive women, there is need of qualitative research that produces in-depth knowledge of a specific condition. The aim of this study was to synthesize HIV-positive women's experiences of sexuality and reproduction as described in qualitative studies.

\section{Methods}

\section{Design}

The methodological design of this meta-synthesis was meta-ethnography as described by Noblit and Hare. ${ }^{14}$ Metasynthesis is research on research, synthesizing the findings of previous primary researchers' qualitative studies. The emphasis in meta-synthesis is on rigorous study selection including contexts and populations, and on careful interpretation of the results across the included studies. The method is designed to generate new integrated theoretical insights, and also hypotheses that can be tested and used in further research. This combination of interpreting findings from systematically selected studies in a particular subject area shares methodological similarities with its quantitative equivalent, meta-analysis. $^{14-17}$

\section{Search strategy and selection criteria}

We performed two systematic searches, one for sexuality and one for reproduction, in the databases Cinahl and Medline for qualitative studies exploring sexuality and/or reproduction in HIV-positive women. Inclusion criteria were scientifically peer-reviewed qualitative studies with HIV-positive women above 18 years old. No language or time restrictions were imposed. Exclusion criteria ruled out studies carried out in countries in the African and Asian continents, studies with quantitative or mixed methods, studies including both sexes, and studies that included only sex-workers (Fig. 1).

All articles meeting the purpose of the study and inclusion criteria were assessed for quality using the Critical Appraisal
FIG. 1. Flowchart summarizing search strategy and selection of studies.
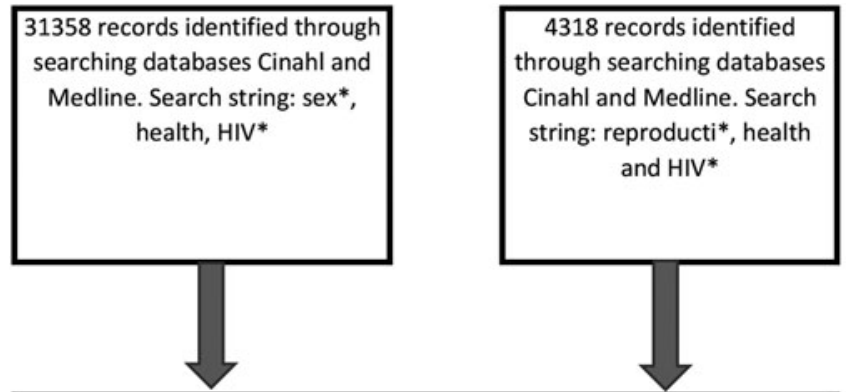

701 records identified after removal of articles with mixed methods,

quantitative studies, mixed sex.

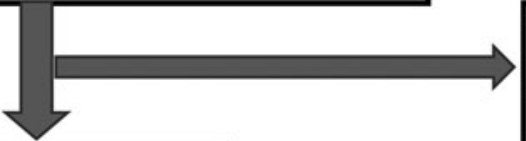

Removal of records that didn't answer the purpose,

mixed methods, mixed sex.

47 full text articles assessed for

eligibility

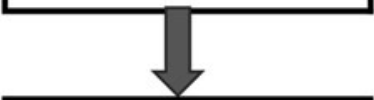

17 full text articles appraised for quality

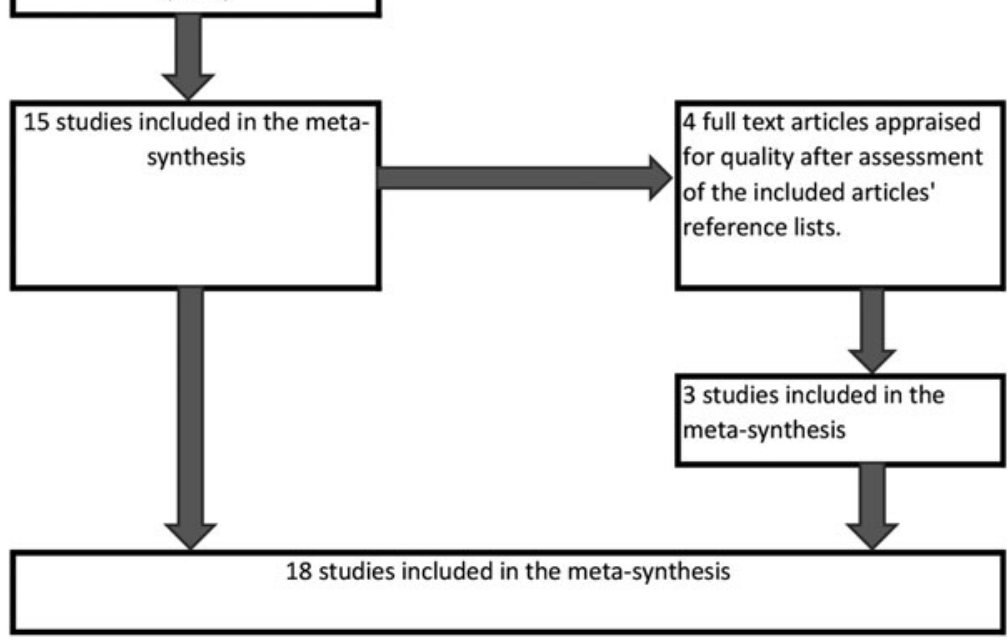




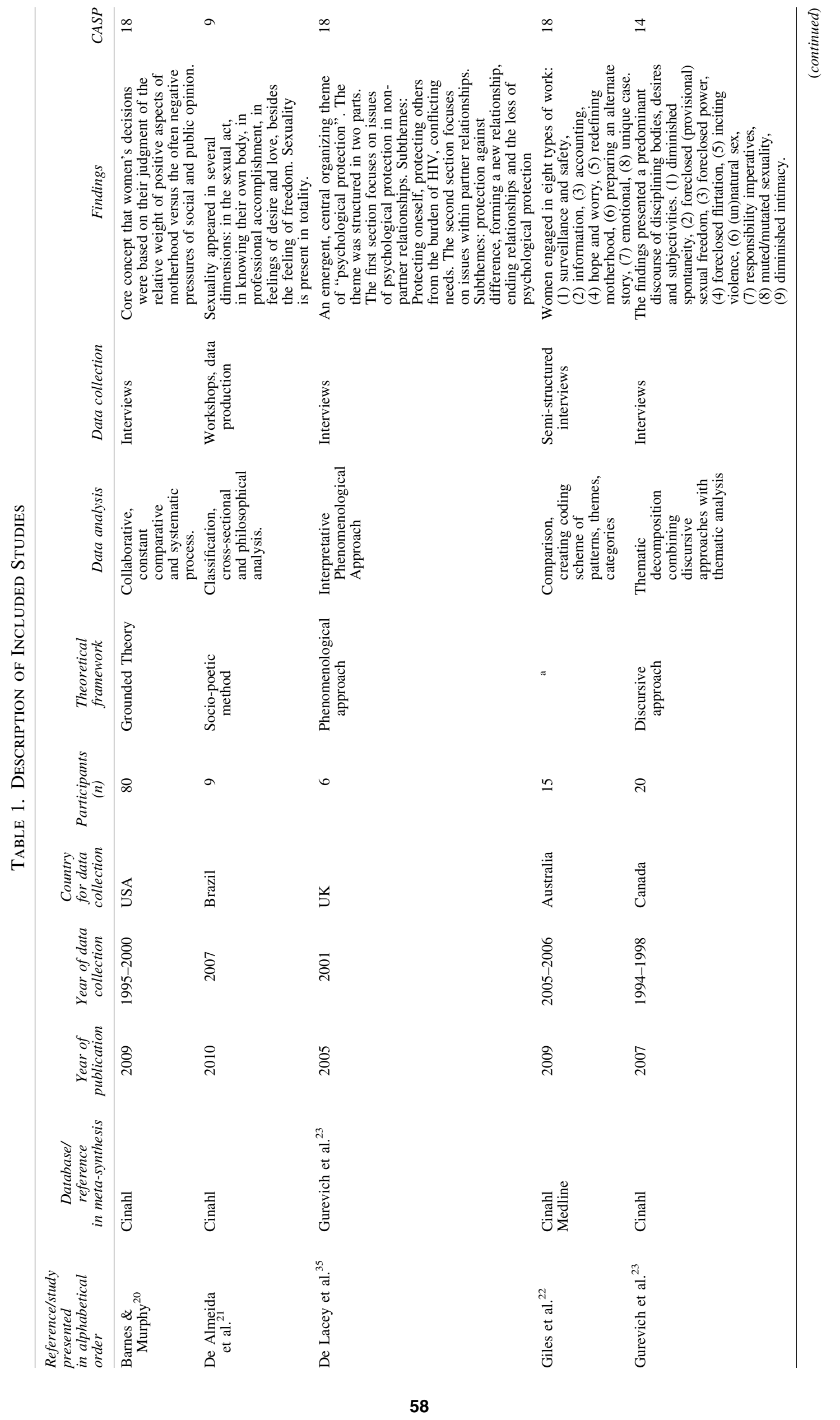




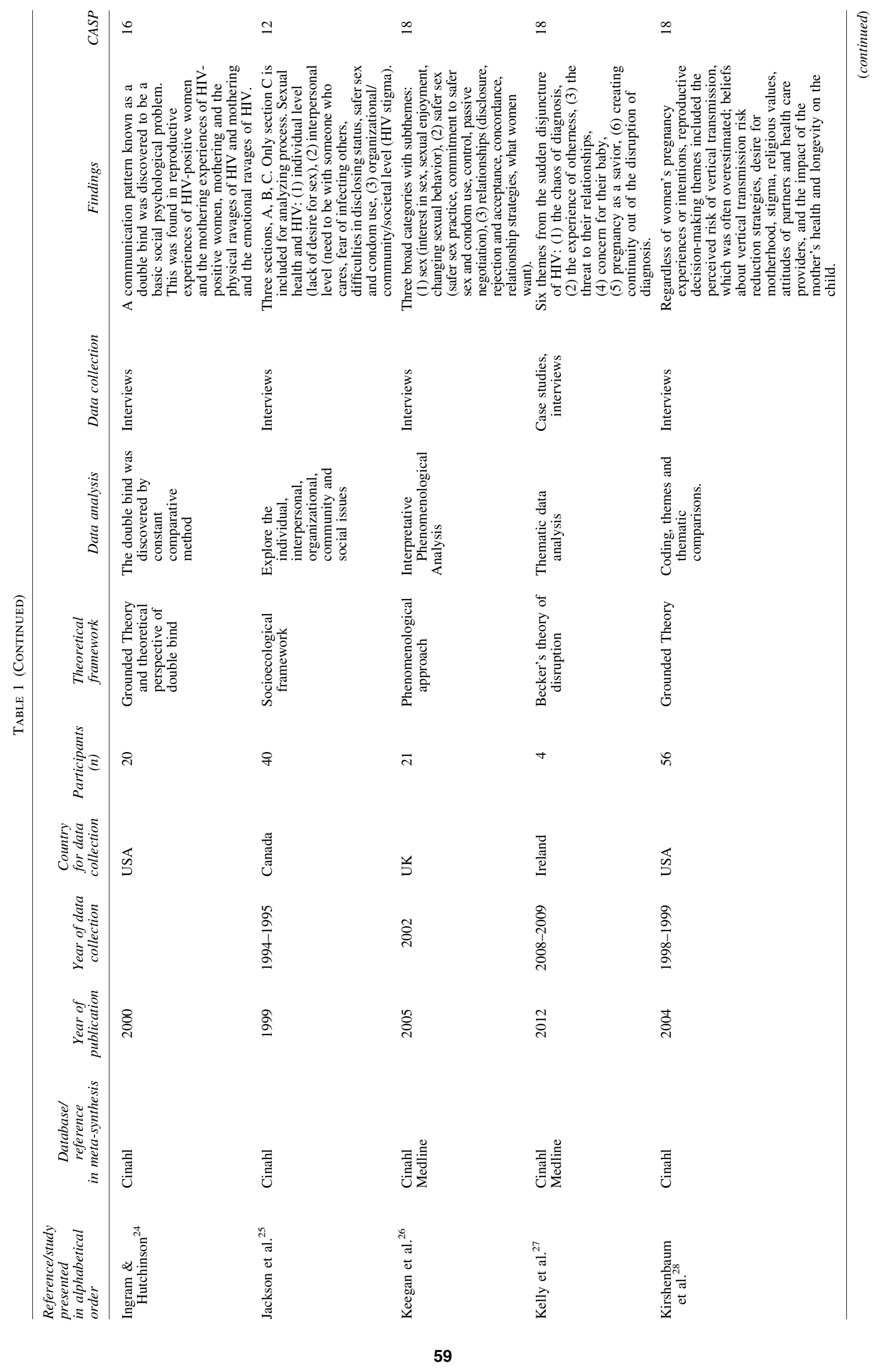




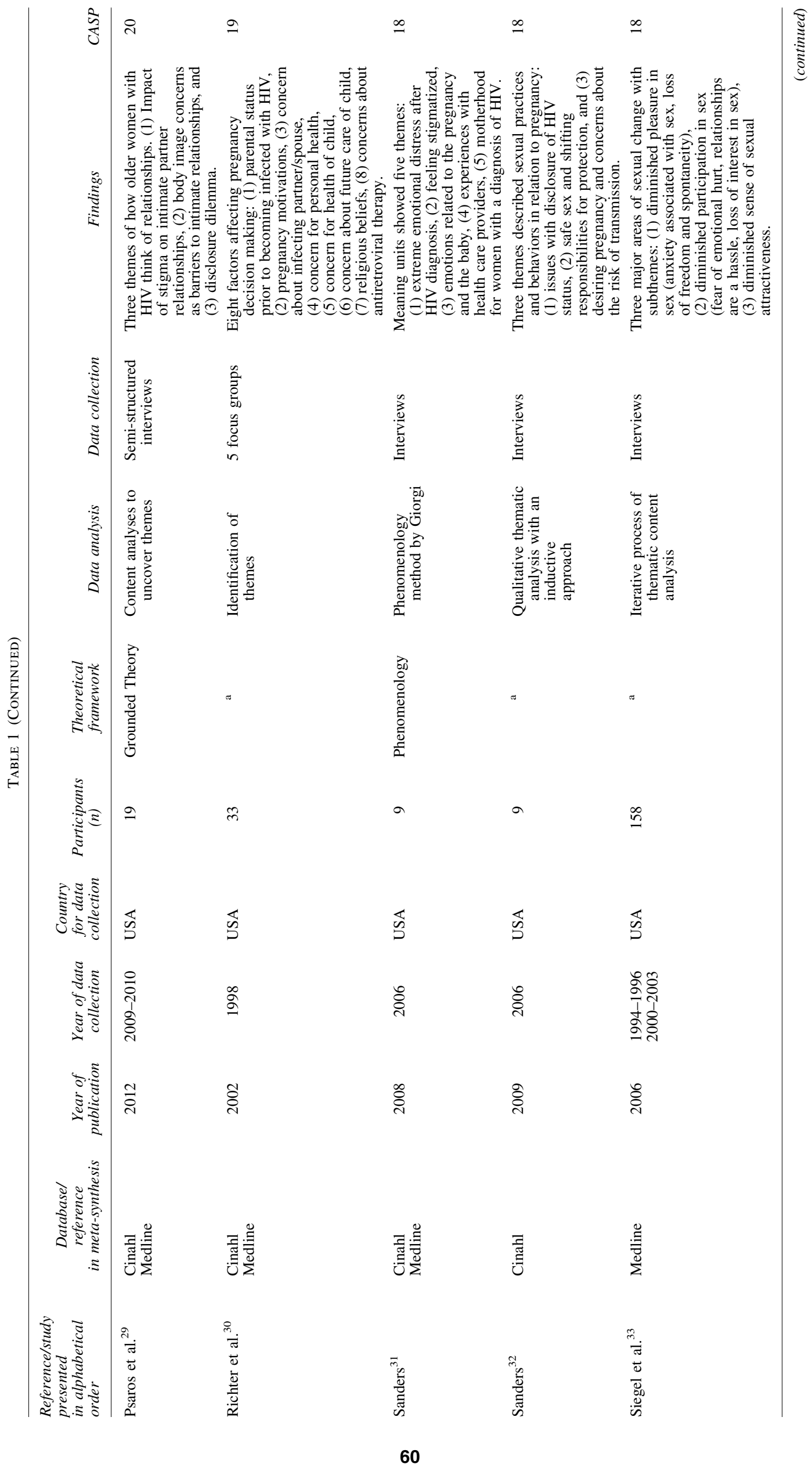




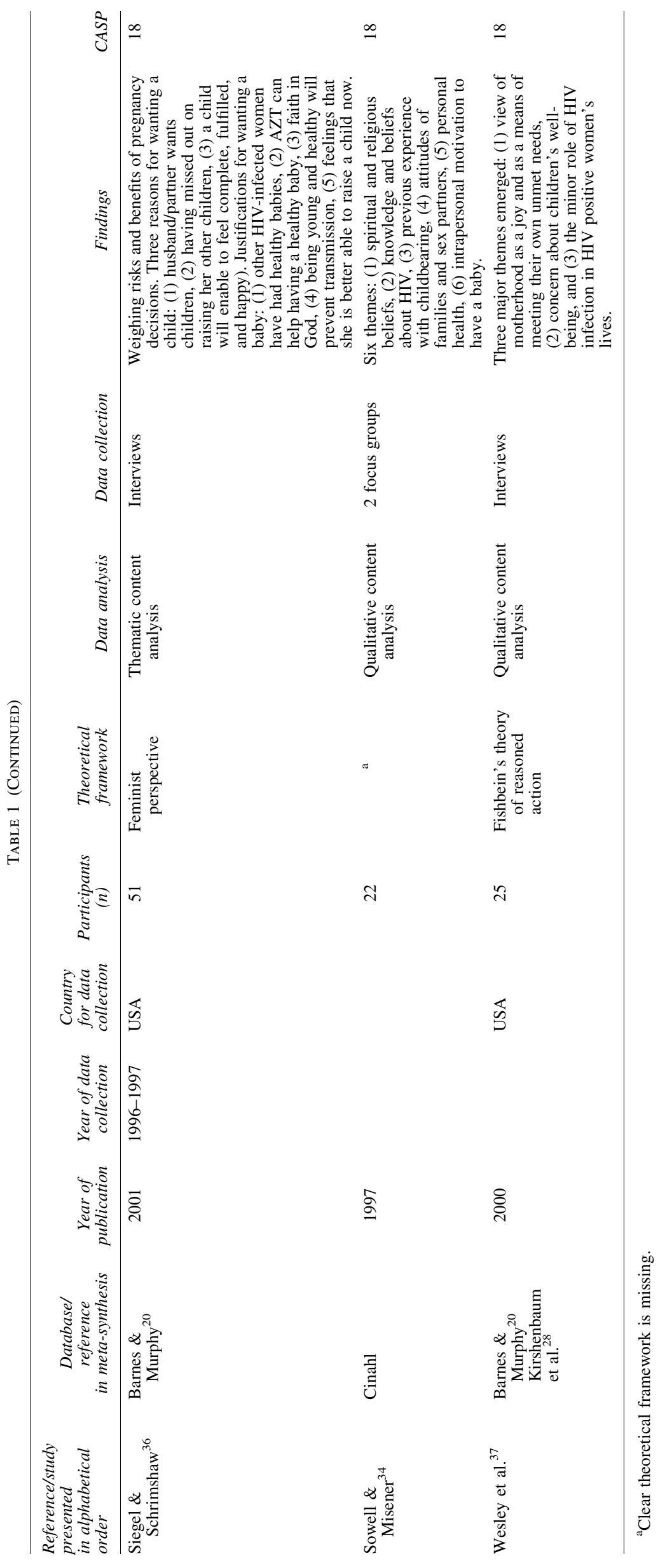


Skills Programme (CASP) consisting of ten questions assessing different aspects of quality in qualitative studies. ${ }^{18}$ Although CASP does not grade the assessment, we graded each question's answer in a scale of 0-2 points, where 2 represents highest quality. Consequently each study could gain a score from 0 to 20 points, where 20 points represents highest quality.

\section{Analysis and synthesis}

The method of Noblit and Hare includes seven overlapping steps. These steps are repeated as the synthesis proceeds, determining how included studies are related, by a process of translating them into one another to achieve a final synthesis of the translations. ${ }^{14}$ The analysis is inspired by grounded theory ${ }^{19}$ and is determined by "theoretical saturation," which is reached when the emerging theory or hypothesis is stable. Included studies can be related to each other as reciprocal translations that add findings from different studies together, refutational translations where study results are in opposition, or by linesof-argument synthesis where parts in a process of comparative analysis generate a new theoretic model to explain the whole. The synthesis describes a higher level of interpretative understanding and presents a new interpreted result. ${ }^{14}$ The included studies in this review covered sexuality and/or reproduction and were assumed to be related to each other, and thus principles of lines-of argument synthesis were followed.

The analysis started with all the authors reading each of the included studies several times. Successively, in repeated readings, descriptions and interpretations were extracted. Categories in each of the study findings were identified, as well as meaning units and key words in their descriptions. Through a process of constant comparisons, findings in each study were compared, juxtaposed and contrasted, and interrelationships were identified. In a comparative process from meta (synthesis) to detail (individual study findings), themes emerged that were modified to encompass all data. Underlying uniformities were also found to enable reformulation until saturation was reached, in that the themes became stable and were shown to cover all study findings. From details to wholeness, the newly generated synthesis was tested by returning to the primary studies.

\section{Results}

\section{Summary and context of included studies}

The search string defined by two of the authors (ECL and $\mathrm{MB}$ ) generated a total of 35,676 records including duplicates, up to March 2014. A total of 701 records remained after excluding duplicates or records fulfilling exclusion criteria. The titles were screened and abstracts read to further eliminate duplicates, studies fulfilling exclusion criteria, or studies not fulfilling the purpose of the meta-synthesis. This process resulted in 47 articles, which were read in full, whereupon 30 articles were excluded because not fulfilling inclusion criteria or the purpose of the meta-synthesis.

The remaining 17 articles were assessed for quality with $\mathrm{CASP}^{18}$ by three of the researchers individually (ECL, MB, and MR). Conflicts in assessments were identified and discussed for reaching assessment agreement. Two of the fulltext articles were excluded because they did not pass the basic quality criteria of CASP. The reference lists of the 15 included studies ${ }^{20-34}$ were examined independently by two researchers in pairs (EC-L and MB, EC-L and MR, EC-L and AM) which resulted in that four additional full-text articles were identified and quality-assessed using CASP by ECL, $\mathrm{MR}$, and MB. One of these studies did not pass the basic quality criteria of CASP, thus three of these studies ${ }^{35-37}$ were included. The procedure is described in Fig. 1.

Consequently we included a total of 18 studies $^{20-37}$ comprising 588 ( $n=4$ to $n=158)$ interviewed HIV-positive women in the lines-of-argument analysis. All authors performed the analysis of the included studies. The studies were published from 1997 to 2012, and performed in six countries: USA $(n=11)$, Canada $(n=2)$, UK $(n=2)$, Australia $(n=1)$, Ireland $(n=1)$, and Brazil $(n=1)$. Individual study characteristics are presented in alphabetical order in Table 1.

\section{Themes}

Six themes constituting a lines-of-argument synthesis were identified. An overview is given in Table 2. In the following presentation, quotes from the original studies are identified with the reference and page.

\section{HIV is a barrier}

The HIV diagnosis appeared as something negative and as a barrier to sexuality and reproduction..$^{20-37}$ It meant being comprehensively affected, ${ }^{21,27,31}$ like "a nightmare,,"27, p.1557 and facing a world-changing experience that gave life a negative dimension. ${ }^{22,28,31}$ De Lacey et al. explained that the women had an HIV-positive identity, where HIV marked their identity. ${ }^{35}$ Living with HIV infection resulted in a change in behaviors and decision-making in relation to sexuality and reproduction. ${ }^{20-22,29,33,35}$

I didn't realize how much HIV was going to be a problem $^{29, \mathrm{p} .757}$

HIV was described as a barrier in sexual partner relationships and sexual actions, and after getting HIV, the women had the experience of having to plan their sexual activity and to inform their sexual partner about their HIV infection.

\section{Ah, it's just always in the bedroom, HIV. It's always there ${ }^{33, \mathrm{p} .7}$}

The barrier also existed in relation to reproduction (i.e., in decision-making around planning for, becoming and being pregnant). The HIV forced the women to weigh decisions between risks and desires in relation to pregnancy. A pregnancy was not only seen as a positive event but included increased concerns and anxiety for health-one's own $^{21-27,29,30,32,33,35}$ and the baby's. ${ }^{20-22,24,25,27,28,30-32,34,36,37}$

Well I did want to have at least two children...but now that I know I'm HIV positive I know I shouldn't. It's not wise for me to have another child because the child could come out infected. ${ }^{37, \text { p. } 298}$

Another barrier appeared to be HIV-related stigma. $^{20,24,25,27-29,31,32,35,36}$ There seemed to be problems regarding how to disclose an HIV-positive status; often this was based on negative experiences and reactions from others. There were descriptions with origins from society and health care service in the past, ${ }^{20,22,24,25,27,28,30,31,33,34}$ which caused guilt and feelings of "being a second-class citizen.",29, p.757

They will put stigma on you real fast, most of the hospitals. Women get the bad end all the way around, especially if they have the virus. ${ }^{31, \text { p.50 }}$ 
Descriptions of how some women developed a strategy called passive negotiation ${ }^{25,26,32}$ were given in the studies, meaning the women used indirect methods to achieve safe sex without explaining why they always wanted to use a condom:

I just told him it was because you don't know where I come from, I don't know where you come from, so it is good to be $\underset{\text { p.650 }}{\text { careful and at the same time I don't want to get pregnant. }}{ }^{26}$,

The women felt that there was a public opinion, and also from health care professionals that HIV-positive women were not supposed to have sex at all and certainly not to become pregnant. ${ }^{20,24,28,31,34}$

The fright on [the health care provider's] face...has stayed within me...it's very hard for a person to hide their bias. ${ }^{28, \mathrm{p} .111}$

\section{Feelings of fear}

The fear in the women's expressions was prominent and a common finding was a strong sense of fear of transmitting HIV to an intimate partner, ${ }^{21,23-27,29,32,33,35}$ which is the most common transmission route of HIV. This concern forced the women to practice safe sex techniques. They showed a strong will and responsibility to not harm others or do what others had done to them. ${ }^{29}$ To protect others from HIV was crucial, ${ }^{23,26,27,29,32,33,35}$ and included informing and giving a partner the opportunity to make an informed choice if exposing oneself to the risk of being infected. ${ }^{35}$ For some women, the fear was so intense that they chose celibacy to be totally sure of avoiding the risk of transmission. ${ }^{23,25,26,29,33}$

I think that's [the sexuality], that's probably the biggest effect on my life; since the diagnosis, we have not had sexual intercourse. And it's not been by his lack of attention or desire. I can't, in my mind, I'm not looking at kind of putting him at risk... ${ }^{23, \mathrm{p} .24}$

Another fear concerned the risk of negatively influencing the health of a fetus/child, both in terms of infecting it with HIV, ${ }^{20-22,24,25,27,28,30-32,34,36,37}$ and also negatively affecting it with ongoing pharmaceutical treatment. ${ }^{22,28,30,37}$ This fear was often connected with feelings of guilt and doubts, which could lead to a decision to avoid childbearing. ${ }^{20,24,28,30,32,37}$

But because of my condition I would not put that child's life in danger. The child could make it or he may not. And that's painful for me to stress out over like that, when I could have prevented it. Even though no matter how bad I wanted it. $^{20,}$ p.484

The fear of transmission of HIV to either partner or child existed often side by side with a strong wish to have an intimate partner relationship ${ }^{26,29,33,35}$ and to give birth to a child $^{20,22,24,28,30-32,34,36,37}$ this made the situation complex because pregnancy requires sex without condom. ${ }^{24,27,28,32}$

The guy I am with is negative. He knows I am positive. I have never had unprotected sex with him, but he wants to know if it is possible to have a baby without him becoming infected. I don't know what to tell him. ${ }^{32, \text { p.66 }}$

The fear also concerned disclosure of one's HIV status to a possible partner-to-be, as it could end in rejection and emotional pain. ${ }^{23,25-29,32,33,35,37}$ This made it more difficult to meet a new partner.
I mean it's the fear of rejection is mainly it, so I thought if I forget about it I don't have to be rejected by anyone. ${ }^{26, \text { p.651 }}$

Fear of disclosing HIV status was also present in women already with an intimate partner, as it could lead to being rejected and being left alone. ${ }^{23,25-29,32,33,35.37}$ Such fear was like an emotional burden, causing distress and creating restrictive relational boundaries. ${ }^{35}$

Even though they say, "well tell a partner you've got it", you're so scared to. It's easy to say that but you're so scared to be rejected to be alone you know, it's hard. ${ }^{23, \mathrm{p} .20}$

But there are also narratives in the studies of when disclosing HIV status it made the women more vulnerable to unhealthy relationships and violence..$^{23,29,33}$ The fear of revealing their positive status meant that several women chose to end partner relationships. ${ }^{22,26,33,35}$ Some women, instead of disclosing their status, formulated alternative stories because of fear of rejection. ${ }^{22}$

To be diagnosed with HIV infection also meant fear for their own health, getting sick and maybe dying. ${ }^{21-27,29,30,32,33,35}$ Some narratives expressed the presence of a struggle between life and death ${ }^{21}$ which included a fear of making one's child an orphan. ${ }^{24,28,34}$ Such fear could lead to more frequent visits to hospitals.

Like I was, like if I had of coughed more than twice a day I would have thought this is it, I am going to die. I would have to go to the hospital. If I had any ache or pain or anything, I had to get checked out cause I was so scared in case I didn't make it to the hospital in time, what if something is wrong...It was just a nightmare. ${ }^{27, \mathrm{p} .1557}$

\section{Feelings of loss}

The expressed change and effect HIV diagnosis had in relation to sexuality and reproduction involved feelings of loss and loss of normality. $22,23,26,27,35,37$ One woman described it as "being thrust into a state of otherness". 27, p.1557 Another woman expressed it as "my lifestyle is wrapped around HIV', 24, p.125 Jarman et al. call this feeling of loss of being normal as having "a dual identity", meaning also having an identity of being HIV-positive. ${ }^{35}$, p.539

Loss was narrated in several studies as a sense of losing a normal sex life, ${ }^{23,33}$ meaning a loss of sexual function, desire, and sexual spontaneity. ${ }^{21,23,25,26,33}$ Loss of physical attraction caused by changed body image because of HIV or medical side effects from ART sometimes impacted the women's sexuality, because of tiredness resulting in decreased desire. ${ }^{21,29,31} \mathrm{~A}$ strong commitment, and sometimes obligation, to always using a condom or other safe sex techniques led to a constrained sexuality. ${ }^{21,23,25,26,32,33,34}$ Constrained sexuality was often presented as less interest in sex, and reduced desire and libido and sexuality lost its spontaneity, meaning less flirtation and less spontaneity in sexual and intimate partner relationships. $^{21,23,25,26,29,32,33,35}$

My sexual life has changed being HIV because it's less spontaneous than it used to be, but it's probably for everybody, the fact of using condoms, the fact that my partner is taking extreme care sometimes, so he's less free also. There are things we don't do anymore, my sexuality has become more constrained. ${ }^{23, \text { p. } 18}$ 
Intimacy and affection are important parts of sexuality and many women often blamed loss of intimacy and affection on condoms, ${ }^{21,23,25,26,29,32,33,35}$ which were often seen as interruptive and which also explained the loss of spontaneity.

...You just can't do whatever, you know, have sex or make love at the spur of the moment. You got to stop, get the condoms, you know. ${ }^{33}$, p.8

Condoms not only caused loss of intimacy and spontaneity, but also loss of equity in relationships. The condom was considered a man's tool but very often the woman's responsibility to initiate and use, which therefore caused an imbalance of power in relationships and sexuality. ${ }^{23,26,29,32}$

I was always the one pushing him to use condoms, and he didn't want to. Eventually when we were living together, I just stopped. It's not always going to be my responsibility to push that...32, p.65

There was loss of freedom for the HIV positive women, in that they couldn't choose freely-what partner to have, or to be pregnant and give birth to a child or not. ${ }^{20-34,36} \mathrm{~A}$ feeling of loss was described in relation to pregnancy and motherhood when different interventions had to be followed in order to avoid mother-to-child transmission of HIV. There was a feeling of loss not to be able to give birth vaginally, and not to breastfeed.

To me a caesarian is a cheating way of having a baby. Things that aren't natural are not meant to be so therefore why force them to happen? That has always been my philosophy and that's why I am in upheaval. ${ }^{22, \mathrm{p} .1234}$

There seemed to be a loss of self-confidence and loss of attractiveness. This was a consequence of a feeling of HIV as an assault on one's body, ${ }^{27,}$ p.1557 like being "contaminated". 25, p.321 The loss of self-confidence and loss of attractiveness included feelings of guilt, dirt, and disgust, $^{21-23,25,27-29,31,33,35}$ and as the following woman expresses, a loss of the womanhood.

Ugly! You know. Like I'm not a woman anymore. ${ }^{33, \mathrm{p} .12}$

The loss of a sense of physical attractiveness and selfconfidence created a sense of hopelessness and belief that they would never be able to find an intimate partner. ${ }^{25,29,33,35}$

Yeah... When it comes to be with my, if I'm having a relationship with somebody or I'm gonna have sex with a partner...I feel disgusting. I feel like I, I can't have sex if I want to. ${ }^{33,}$ p.13

\section{Motherhood}

Despite HIV being a barrier in relation to pregnancy and childbirth, motherhood was often experienced as something positive. Many women expressed a strong desire to be pregnant and give birth. It was connected with normality; to feel like a "real woman", 37, p.297 to feel whole and complete. $^{20,22,24,25,27,30,31,34,36,37}$

\section{It is sort of like a completion of myself as a woman. ${ }^{31, \mathrm{p} .54}$}

There were also stories given that motherhood and raising a child signified a new chance in life, starting something new. ${ }^{20,31,36,37}$ Pregnancy itself and the following motherhood were even explained as a savior. ${ }^{27}$
...I treat this child like the kids that I lost. That makes me very optimistic and hopin' that this one do better than I have, in my lifetime. $^{35, \text { p.487 }}$

To be a mother, and fulfill the needs of a child, was connected with care and unconditional love, and also with hope. ${ }^{29,37}$ Some women had experiences of not being able to take care of a child in the past due to drug abuse..$^{20,31,36} \mathrm{~A}$ baby provided unconditional love, ${ }^{24}$ and was also a metaphor for hope. ${ }^{27}$ The hope was expressed as the baby was a reason to live and represented going from death to life. ${ }^{20}$ The baby gave a reason to look forward toward the future. ${ }^{20,22,24,25,27,28,30,36,37}$

I want to be there for someone. I want to watch someone grow, and help them grow into a person who cares about others, and tries to do right. ${ }^{20, \mathrm{p} .486}$

That I have to be there and I have to take care of them and they need to be fed. It fulfills me, my mind, mentally, spiritually, and within my gut, my soul, I feel full. You know it makes me feel that I wasn't just put on this world to be here, I was here for a reason. ${ }^{24, \text { p. } 117}$

He gives me reasons to live. ${ }^{25, \mathrm{p} .125}$

Motherhood also provided a social value. ${ }^{20,22}$ Being a mother was considered as a personal fulfillment that provided respect in the community:

I think that having a child is one of the greatest things you can do. If you haven't had one, you've missed a lot. It's something that a man can't do. ${ }^{24, \mathrm{p} .122}$

\section{Spiritual beliefs}

To have a faith, a spiritual belief, was another positive dimension which gave support and strength to the women. Trust in God or belief in a higher power also appeared to influence reproductive decisions in a positive way. The belief gave hope, faith, and trust. ${ }^{20,28,30,34,36,37}$ The relationship with God was described as a positive personal relationship and a trustworthy connection. God was experienced as someone confirming women's choices in relation to sexuality and reproduction.

\section{I talk to people and I just look at their reactions... some people have positive reactions and some have negative reactions. But basically, it's a decision I made with my higher power. I just ask God to show me what to do. He allows this pregnancy to go all the way, I'm going to have it, and I hope it's a little girl. $^{20,}$ p.484}

To have a baby was by many women expressed as a gift from God, something magical. God would protect. Many women passed the responsibility from themselves to God. Some believers did not see abortion as an option:

I'll leave it in God's hands. I mean, you know, if it wasn't meant for me to be pregnant, God wouldn't put it there... ${ }^{36, \text { p.119 }}$

\section{Supportive relationships}

The need for social support was very strong among the women. Support could be given by persons in different situations and positions. ${ }^{20-23,25-32,34-37}$ Prominent in the women's stories was the support from other persons or women living with HIV. ${ }^{20,22,30,34,36}$ "Who's better to talk on these issues than someone who is actually living it?",30, p.93. 
Table 2. Initial Categories, References, Emerging Themes, and Final Six Themes

\begin{tabular}{|c|c|c|c|}
\hline $\begin{array}{l}\text { Initial categories } \\
\text { (findings from } \\
\text { primary papers) }\end{array}$ & References & Emerging themes & Final six themes \\
\hline $\begin{array}{l}\text { Sexuality and } \\
\text { reproduction in } \\
\text { relation to HIV }\end{array}$ & $\begin{array}{r}20,21,22,23,24,25,26,27,28 \\
29,30,31,32,33,34,35,36,37\end{array}$ & $\begin{array}{l}\text { In sexuality and reproduction, } \\
\text { HIV is considered as a problem } \\
\text { and something negative. HIV } \\
\text { means a negative change. }\end{array}$ & 1. HIV is a barrier \\
\hline \multirow{3}{*}{$\begin{array}{l}\text { Problems with } \\
\text { disclosing HIV } \\
\text { status }\end{array}$} & $23,25,26,27,28,29,32,33,35,37$ & $\begin{array}{l}\text { Fear of disclosing HIV status to a } \\
\text { partner and fear of rejection. }\end{array}$ & \multirow[t]{3}{*}{$\begin{array}{l}\text { 1. HIV is a barrie } \\
\text { 2. Fear }\end{array}$} \\
\hline & $20,22,24,25,27,28,29,30,31,33,34,35,37$ & & \\
\hline & $20,24,25,27,28,29,31,32,35,36$ & HIV-related stigma & \\
\hline \multirow[t]{3}{*}{ Transmission of HIV } & $21,23,24,25,26,27,29,32,33,35$ & $\begin{array}{l}\text { Fear of transmitting HIV to an } \\
\text { intimate partner }\end{array}$ & \multirow[t]{3}{*}{ 2. Fear } \\
\hline & $\begin{array}{l}20,21,22,24,25,27,28,30,31, \\
\quad 32,34,36,37\end{array}$ & Fear of transmitting HIV to baby & \\
\hline & $23,26,27,29,32,33,35$ & $\begin{array}{l}\text { Feeling responsibility and feeling } \\
\text { of need to protect others because } \\
\text { of fear of transmitting HIV. }\end{array}$ & \\
\hline \multirow{2}{*}{$\begin{array}{l}\text { Body change- in } \\
\text { relation to } \\
\text { sexuality and } \\
\text { reproduction }\end{array}$} & $\begin{array}{l}21,22,23,24,25,26,27,29,30 \\
32,33,35\end{array}$ & $\begin{array}{l}\text { Fear of body changes, medical } \\
\text { side effects, getting sick and } \\
\text { dying. }\end{array}$ & 2. Fear \\
\hline & $21,22,23,25,27,28,29,31,33,35$ & $\begin{array}{l}\text { Having a negative self-image } \\
\text { because of HIV, for example, } \\
\text { guilt and shame. Feeling ugly } \\
\text { and unattractive. }\end{array}$ & 3. Loss \\
\hline Normality & $22,23,26,27,35,37$ & $\begin{array}{l}\text { Getting HIV means a state of } \\
\text { otherness, feeling incomplete. }\end{array}$ & 3. Loss \\
\hline \multirow{5}{*}{$\begin{array}{l}\text { Sexual activity and } \\
\text { intimate partner } \\
\text { relations }\end{array}$} & $21,23,25,26,33$ & $\begin{array}{l}\text { Having less sexual desire/libido } \\
\text { and interest in sex }\end{array}$ & \multirow{5}{*}{$\begin{array}{l}\text { 1. HIV is a barrie } \\
\text { 2. Fear } \\
\text { 3. Loss }\end{array}$} \\
\hline & $21,23,25,26,29,32,33,35$ & $\begin{array}{l}\text { Experiencing less intimacy and } \\
\text { affection }\end{array}$ & \\
\hline & $21,23,25,26,32,33$ & $\begin{array}{l}\text { Experiencing less sexual } \\
\text { spontaneity, for example, in } \\
\text { flirtation or sexual activity, } \\
\text { because of concerns regarding } \\
\text { safe sex. }\end{array}$ & \\
\hline & $23,25,26,29,32,33$ & $\begin{array}{l}\text { Feeling a loss of power in } \\
\text { relationships and sex. Feeling } \\
\text { loss of freedom to choose. }\end{array}$ & \\
\hline & $21,23,25,26,32,33,34$ & Safe sex and condom use & \\
\hline \multirow[t]{5}{*}{$\begin{array}{l}\text { Pregnancy, } \\
\text { motherhood and } \\
\text { HIV }\end{array}$} & $\begin{array}{l}20,21,22,24,25,27,28,30,31, \\
\quad 32,34,36,37\end{array}$ & $\begin{array}{l}\text { HIV means that you have to weigh } \\
\text { your decisions about pregnancy. } \\
\text { For example, desire and risks. }\end{array}$ & $\begin{array}{l}\text { 1. HIV is a barrier } \\
\text { 2. Fear }\end{array}$ \\
\hline & $20,22,24,25,27,30,31,34,36,37$ & $\begin{array}{l}\text { Pregnancy is a part of normality, } \\
\text { gives an identity of being a } \\
\text { woman. }\end{array}$ & 4. Motherhood \\
\hline & $20,22,24,25,27,28,30,36,37$ & $\begin{array}{l}\text { Pregnancy gives reason to live, } \\
\text { gives hope for the future }\end{array}$ & \\
\hline & $20,31,36,37$ & A second chance & \\
\hline & $20,28,30,34,36,37$ & $\begin{array}{l}\text { God or a higher power influence } \\
\text { reproductive decisions in a } \\
\text { positive way, affirming } \\
\text { reproductive choices }\end{array}$ & 5. Spiritual beliefs \\
\hline \multirow[t]{2}{*}{$\begin{array}{l}\text { What do women } \\
\text { need and want? }\end{array}$} & $\begin{array}{l}20,24,26,27,29,31,34,35,37 \\
21,25,26,29,35,36\end{array}$ & $\begin{array}{l}\text { A feeling of normality } \\
\text { Relationships and a feeling of } \\
\text { being loved }\end{array}$ & \multirow[t]{2}{*}{$\begin{array}{l}\text { 6. Supportive } \\
\text { relationships }\end{array}$} \\
\hline & $\begin{array}{l}20,21,22,23,25,26,27,28,30,31 \\
\quad 32,34,35,36,37\end{array}$ & $\begin{array}{l}\text { Support and information, both to } \\
\text { cope with feelings and for } \\
\text { practical information. }\end{array}$ & \\
\hline
\end{tabular}


As for all women and not only HIV-positive women, it seemed important to have a supportive intimate partner ${ }^{35}$ and women expressed that this feeling of being normal seemed strengthening and part of supportive actions. ${ }^{20,24,26,27,29,31,34,35,37}$ They expressed a needing and wanting; to have a partner and to be loved. $^{21,25,26,29}$

$$
\text { I want to grow old with somebody, you know. }{ }^{29, \text { p.757 }}
$$

It seemed important to have a relationship where you could be open and conceal your HIV status and be protected for negative feelings related to HIV diagnosis, ${ }^{35}$ and it was especially supporting and desirable to feel normal and not to be forced to act differently from other women. . $^{24,26,27,29,31,34,35,37}$ An intimate partner relationship could offer protection from feelings of otherness:

You know, from being abnormal for x number of years and from being different I was suddenly the same as everybody else..$^{35}$. .542

There appeared to be a need for support for the women to handle guilt, which was central in narratives from women who had not disclosed their HIV status. ${ }^{25,27,35}$ There appeared to be a strong desire to tell others about HIV, but at the same time fear negative reactions, needed. There was a need for support regarding when and how to disclose their HIV status. ${ }^{35}$

\section{How do you tell people? How do you go to a relationship and then say, when you move onto a sexual relationship, "Oh by the way I'm HIV-positive." How do you do that? What if they reject you? You've then got on your conscience what if they've told other people. Because who knows, I've a son who I don't want to know. ${ }^{28,}$. 543}

The women expressed that a good relationship with health care professionals was important for gaining support. ${ }^{20-22,}$ 24-26-28,30-32,34,36 In this support the women had a need for concrete and objective information about family planning, medical risks, and preventive interventions in pregnancy. If interventions to eliminate transmission of HIV to the baby had to be made, practical information was very important to motivate the mothers and explain the interventions to them. ${ }^{22,28,30,37,34}$ Insecurity about safe sex techniques was articulated and a need for practical information and discussion about these subjects was expressed. ${ }^{21,23,25,26,33}$

I look for things that are safe $100 \%$...there have not been recorded cases of anyone becoming infected (in oral sex)...so I thought that's $100 \%$ safe...so like a month later I was reading another one of these small leaflets and it says although the risk is small there is some risk and...I started to become a bit paranoid... ${ }^{26}$, p.649

There were also stories about experiences of being treated differently by health care professionals because of their HIV infection, ${ }^{37}$ and the studies also state that it is important that health care providers view the women's lives as a whole and not just the disease, HIV-infection. Sometimes health care providers focused on HIV status too much.

Talking about HIV really gets you upset, so what you do is just don't talk about it much. ${ }^{37, \text { p.299 }}$

\section{Lines-of-argument synthesis: Balancing the burden of HIV infection in relation to sexuality and reproduction}

The six identified themes show that HIV infection for the HIV-positive women is a burden in relation to sexuality and reproduction. The burden is however not constant; it can be heavier or lighter. Conditions making the HIV burden heavier are: HIV as a barrier, feelings of fear and feelings of loss, whereas motherhood, spiritual beliefs, and supportive relationships make the HIV burden lighter.

\section{Discussion}

This meta-synthesis shows that HIV infection is a burden for HIV-positive women in relation to their sexuality and reproduction. The factors making the burden heavier and thus negatively impacting on one's sexuality and reproduction are well known. Earlier studies show that HIV-positive women have presented significantly higher degrees of sexual problems compared with uninfected women, and significantly lower scores in sexual desire, activity, and satisfaction compared to women without HIV. ${ }^{38,39}$ Sexual desire or condom use alone are, however, not enough to explain the complexity of sexuality and reproduction ${ }^{1}$ and sensing HIV as a burden.

Despite a positive trend of lowering the transmission rate of HIV to one's partner or baby due to ART, probably well known for a majority of the participating women, the fear of transmission was highly present in our study and showed a significant impact in their lives. ${ }^{20-37}$ Our study shows that the fear of transmitting HIV to a partner was prominent. ${ }^{21,23-27,}$ 29,32,33,35 Modern ART has effectively reduced the sexual transmission risk of HIV, ${ }^{40-45}$ but even if the real risk of transmission was low for the majority of participating women, the fear of transmission probably still affected them. There was also a prominent fear of transmitting HIV to one's baby, ${ }^{20-22,24,25,27,28,30-32,34,36,37}$ which echoes findings in earlier studies. ${ }^{9,10}$ Like the strongly reduced risk of HIV transfer to one's partner, the risk of transmitting HIV to one's baby is almost eliminated, at least in resource-rich settings when the HIV infection is detected early and women don't breast-feed. $^{46,47}$

This fear of transmitting HIV to a partner or child is also related to the risk of being stigmatized, a concept introduced in the early $1960 \mathrm{~s},{ }^{48}$ and this can explain why for many participating women it was really challenging to disclose one's HIV-positive status. ${ }^{20,22-37}$ Nondisclosure of one's serostatus to a partner has been described previously, for example in a study of HIV-infected young women carried out in the United States. ${ }^{12}$ In our study, the stigma and psychological problems were shown in the form of rejection, avoidance, shame, and despair.

A literature review shows that the consequences of HIVrelated stigma may lead to mental illness and medication adherence issues, ${ }^{49}$ and research exploring stigma and sexuality show direct connections between stigma, psychological distress and sexual risks. ${ }^{50,51}$ It therefore appears to be of importance that the general public also need information about the effectiveness of ART and HIV transmission. To decrease ignorance of HIV transmission can in the long-term decrease HIV-related stigma and promoting better well-being for HIV-positive persons.

However, the negative feelings of HIV are not only connected to sexuality and reproduction for women living with HIV. It also means being on ART for the rest of one's life, possibly affecting the body's appearance, sexual attractiveness, and causing other side effects or teratogenicity. ${ }^{29,33}$ 
Other barriers for ART adherence has been described, such as limited control over treatment options, ART's impact on the body, inconsistent access to ART, and subsequent inability to take art as prescribed. ${ }^{52}$

The meta-synthesis showed that feelings of loss and of not being normal also made the burden of HIV heavier, ${ }^{22,23,26,27,35,37}$ and this is related to the fear of losing "a normal sex life" as a consequence of being obliged to maintain safe sex techniques such as use of a condom. The problems related to condom use have been described earlier. $^{53-56}$ Sarkar $^{56}$ has found non-use of a condom during a sexual intercourse to be related to ethical and religious values. It is suggested that many women in an intimate relationship avoid condom use due to fear of being suspected of being unfaithful and/or promiscuous. This action was also shown in our data, and suggests that we as health care professionals in HIV prevention not only should focus on condom use but also offer other strategies such as early treatment to reduce HIV viral load and pre-exposure prophylaxis to a HIV-negative partner.

Motherhood was identified as making the burden of being HIV-positive easier to bear. ${ }^{20,22,24,25,27,28,30,31,34,36,37}$ That motherhood is a strengthening condition has also been described in women living with other chronic diseases-for example, type 1 diabetes, a condition that increases the risk for both malformations and complications in relation to childbirth. ${ }^{57}$ All women with increased ill health risks in relation to childbearing need to weigh their own desires against risks for both their own and the child's health. ${ }^{58}$

Spiritual belief was a strengthening condition for the women with HIV. ${ }^{20,28,30,34,36,37}$ The way that spiritual beliefs can be a buffer when facing negative life situations, such as living with HIV, has already been described. ${ }^{59}$ These findings suggest that spirituality has to be considered part of a holistic professional care of HIV positive persons. Health care professionals should consider and ask about patients' need for spiritual support, regardless of whether the health care professionals themselves have a personal faith.

Another important factor identified as reducing the burden of living with HIV in relation to one's sexuality and reproduction, was getting support. ${ }^{20-23,26-28,30-32,34-37}$ Social support is multidimensional and contains provision of instrumental aid, information, and emotional sustenance and affirmation. ${ }^{60}$ To get a chronic disease is, according to Bury, a disruptive event. ${ }^{61}$ Based on studies on persons with chronic diseases such as diabetes and AIDS, ${ }^{62}$ it has been suggested that normalization can be a form of coping and adapting to having a chronic illness. ${ }^{63}$ To have a feeling of being and being treated as normal seemed important and had a supportive and strengthening function. ${ }^{20,24,26,27,29,31,34,35,37}$ In the end, the women did not want to be treated as abnormal women. They wanted professional and objective care without judgment and bad treatment because of their HIV status.

\section{Study limitations}

One limitation of this study is that we excluded studies carried out in countries on the African and Asian continents, due to sometimes low accessibility to ART and issues related to high poverty. This might impact external validity and thus the study's result might not be generalized in all populations. However, the methodology of Noblit and Hare's meta- synthesis, does not result in generalizations, but translations, ${ }^{14}$ meaning that the theoretical insights arising from the synthesis of the included studies should be transferable to other similar settings and contexts. ${ }^{15}$

Transferability cannot occur unless the material has detailed, meaning-rich descriptions of the participants, ${ }^{64}$ which are included in this meta-synthesis. Some of the included studies were conducted before 1997, when ART was not widely used or accessible, which might have made the burden of HIV heavier in those contexts. Since ART has reduced the morbidity and mortality of HIV-infection and decreased the risk of transmission in sexual- and mother-to-child transmission, this would probably have reduced the burden of fear for some of these women in the included studies.

\section{Clinical implications}

In holistic care, it is important for health care professionals to see the women as whole individuals and not only focus on the disease. The result emphasizes the strength of support from health care professionals. But support is not only offering information; support is also about listening. There were narratives in the included studies of experiences of violence, which the women might need help to handle. As health care professionals, we have to ask and be open to stories of, for example, rape, or abuse. Supporting selfacceptance and awareness are only a few of the many areas where care providers outside the medical context can be important for patients' ongoing well-being. ${ }^{8}$ The importance of support from other HIV-positive women is emphasized in the meta-synthesis. ${ }^{20,22,30,34,36}$ Even though it is difficult for some women to attend support meetings like this, as it means they have to disclose their HIV-positive status, it is important to motivate women to meet other HIV-positive persons.

As mentioned above, there is a need for information about ART, HIV transmission, and, if needed, individual guidance about safe sex practices. Information given has to be adjusted to individual needs and health care providers also have to provide instructions on ways to cope with negative feelings of living with HIV. It is important for health care professionals to talk about pregnancy and discuss the options available for patients who have a wish or intention to get pregnant. If women lack support from family members, support from health care providers may be even more important. ${ }^{65}$

There is a need for practical information about contraceptives, medical risks, and interventions related to the risk of HIV transmission and barriers between fertility intentions, and pregnancy seeking behavior also need to be illuminated. ${ }^{65}$ Women actively trying to conceive intend not to talk with their provider about safer conception strategies and they expressed confusion and concern on how to conceive safely. ${ }^{66}$ Reproductive counseling initiated by health care providers is needed to reduce risk of transmission to partners and infants, which can have major health implications. ${ }^{66}$

Disclosure of HIV-positive status seems problematic, and some women may need the presence of a health care professional when the disclosure is made. ${ }^{67}$ Everything has to be done without judgment; it is important for health care professionals not to relate to their personal sexual behaviors as the sexual norm.

In clinical practice, it might be of importance to address all these conditions that make the burden easier, to support 
pregnancy, to support the desires of these women, and to help them cope with negative feelings, in order to promote the sexual and reproductive health of HIV-positive women.

To conclude, the meta-synthesis shows that HIV in relation to sexuality and reproduction for the women was a burden. However the weight of the burden was not constant; it could be heavier or lighter. The study demonstrates possibilities to enhance the burden by emphasizing on the positive conditions that were identified. In future research there is a need to focus not only on examining how HIV-positive women's sexual and relational lives manifest themselves, but also on how health care professionals should provide adequate support to the women in relation to sexuality and reproduction.

\section{Acknowledgments}

This research was funded by the Research Council Södra Älvsborg Sweden; Södra Älvsborg Hospital Borås Sweden; the Swedbank Sjuhärad's Foundation for Research at the Södra Älvsborg Hospital Borås Sweden; Alice Swenzon's Foundation for scientific research.

\section{Author Disclosure Statement}

No competing financial interests exist.

\section{References}

1. World Health Organization (WHO). Defining sexual health. Available at: http://www.who.int/reproductivehealth/topics/ sexual_health/sh_definitions/en/(Last accessed June 5, 2015).

2. Yadav J, Gennarelli LA, Ratakonda U. Female sexuality and common sexual dysfunctions: Evaluation and management in a primary care setting. Prim Care Update OB/ GYNS 2001;8:5-11.

3. Loos J, The Eurosupport 5 Study G, Nöstlinger C, et al. Mirror, mirror on the wall: The face of HIV + women in Europe today. AIDS Care 2010;22:919.

4. World Health Organization (WHO). HIV/AIDS; Keyfacts. Available at: http://www.who.int/mediacentre/factsheets/ fs360/en/ (Last accessed December 19, 2015).

5. World Health Organization. Women and Health. Today's evidence, tomorrow's agenda. Available at: http://whqlibdoc .who.int/hq/2009/WHO_IER_MHI_STM.09.1_eng.pdf?ua=1 (Last accessed February 10, 2015).

6. Lohse N, Gerstoft J, Kronborg G, et al. Comorbidity acquired before HIV diagnosis and mortality in persons infected and uninfected with HIV: A Danish Population-Based Cohort Study. JAIDS 2011;57:334-339.

7. Reiss P, Sighem AIv, Brinkman K, Gras LA, de Wolf F, ANOC study. Life expectancy of recently diagnosed asymptomatic HIV-infected patients approaches that of uninfected individuals. AIDS 2010;24:1527-1535.

8. Ball SC. Increased longevity in HIV: Caring for older HIVinfected adults. Care Manag J 2014;15:76-82.

9. Ray S. Sexual health for people living with HIV. Reprod Health Matters 2007;15:67-92.

10. Hankins C, Gendron S, Tran T, Lamping D, Lapointe N. Sexuality in Montreal women living with HIV. AIDS Care 1997;9:261-271.

11. Bharat S, Mahendra VS. Meeting the sexual and reproductive health needs of people living with HIV: Challenges for health care providers. Reprod Health Matters 2007;15:93-112.

12. Carter MW, Kraft JM, Hatfield-Timajchy K, et al. The reproductive health behaviors of HIV-infected young women in the United States: A literature review. AIDS Patient Care STDS 2013;27:669-680.

13. Brickley DB, Almers L, Kennedy CE, et al. Sexual and reproductive health services for people living with HIV: A systematic review. AIDS Care: Psychol Sociomed Aspects AIDS/HIV 2011;23:303-314.

14. Noblit GW, Hare RD. Meta-Ethnography: Synthesizing Qualitative Studies. Sage Publications, Inc., 1988.

15. Sandelowski M, Docherty S, Emden C. Focus on qualitative methods. Qualitative metasynthesis: Issues and techniques. Res Nurs Health 1997;20:365-371.

16. Bondas T, Hall EO. Challenges in approaching metasynthesis research. Qual Health Res 2007;17:113-121.

17. Finlayson KW, Dixon A. Qualitative meta-synthesis: A guide for the novice. Nurse Res 2008;15:59-71.

18. Critical Appraisal Skills Programme (CASP). CASP Checklists. Available at: http://media.wix.com/ugd/dded87_ 951541699e9edc71ce66c9bac4734c69.pdf (Last accessed February 16, 2015).

19. Glaser BG, Strauss AL. The Discovery of Grounded Theory: Strategies for Qualitative Research. New York: Aldine De Gruyter, 1967.

20. Barnes DB, Murphy S. Reproductive decisions for women with HIV: Motherhood's role in envisioning a future. Qual Health Res 2009; 19:481-491.

21. de Almeida ANS, Silveira LC, da Silva MRF, Araújo MÂM, Guimarães TA. Subjectivity and sexuality production in women living with HIV/AIDS: A sociopoetic production. Revista Latino-Am Enfermagem 2010;18:163-169.

22. Giles ML, Hellard ME, Lewin SR, O'Brien ML. The "work" of women when considering and using interventions to reduce mother-to-child transmission (MTCT) of HIV. AIDS Care 2009;21:1230-1237.

23. Gurevich M, Mathieson CM, Bower J, Dhayanandhan B. Disciplining bodies, desires and subjectivities: Sexuality and HIV-positive women. Fem Psychol 2007;7:9-38.

24. Ingram D, Hutchinson SA. Double binds and the reproductive and mothering experiences of HIV-positive women. Qual Health Res 2000;10:117-132.

25. Jackson LA, Millson M, Calzavara L, et al. Community HIV prevention: What can we learn from the perceptions and experiences of HIV-positive women living in metropolitan Toronto, Canada? Int Quart Comm Health Edu 1998;18:307-330.

26. Keegan A, Lambert S, Petrak J. Sex and relationships for HIV-positive women since HAART: A qualitative study. AIDS Patient Care STDs 2005;10: 645-654.

27. Kelly C, Alderdice F, Lohan M, Spence D. Creating continuity out of the disruption of a diagnosis of HIV during pregnancy. J Clin Nurs 2012;21:1554-1562.

28. Kirshenbaum SB, Hirky AE, Correale J, et al. "Throwing the Dice": Pregnancy decision-making among HIVpositive women in four U.S. cities. Persp Sex Reprod Health 2004;36:106-113.

29. Psaros C, Barinas J, Robbins GK, Bedoya CA, Safren SA, Park ER. Intimacy and sexual decision making: Exploring the perspective of HIV positive women over 50. AIDS Patient Care STDs 2012;26:755-760.

30. Richter DL, Sowell RL, Pluto DM. Factors affecting reproductive decisions of African American women living with HIV. Women Health 2002;36:81-96.

31. Sanders LB. Women's voices: The lived experience of pregnancy and motherhood after diagnosis with HIV. J Assoc Nurses AIDS Care 2008;19:47-57. 
32. Sanders LB. Sexual behaviors and practices of women living with HIV in relation to pregnancy. J Assoc Nurses AIDS Care 2009;20:62-68.

33. Siegel K, Schrimshaw E, Lekas H-M. Diminished sexual activity, interest, and feelings of attractiveness among HIVinfected women in two eras of the AIDS epidemic. Arch Sex Behav 2006;35:437-449.

34. Sowell RL, Misener TR. Decisions to have a baby by HIVinfected women. West J Nurs Res 1997;19:56-70.

35. De Lacey G, Walsh S, Jarman M. Keeping safe, keeping connected: A qualitative study of HIV-positive women's experiences of partner relationships. Psychol Health 2005; 20:533-551.

36. Siegel K, Schrimshaw EW. Reasons and justifications for considering pregnancy among women living with HIV/ AIDS. Psychol Women Quart 2001;25:112-123.

37. Wesley Y, Smeltzer SC, Redeker NS, Walker S, Palumbo $\mathrm{P}$, Whipple B. Reproductive decision making in mothers with HIV-1. Health Care Women Int 2000;21:291-304.

38. Wilson TE, Girardin J-L, Schwartz R, et al. HIV infection and women's sexual functioning. Acquir Immune Defic Syndr 2010;54:360-367.

39. Denis A, Hong S-M. Sexual functioning of women with HIV: A comparison with non-HIV women. Can J Human Sex 2003;12:97-107.

40. Cohen MC, Ying QC, McCauley M, et al. Prevention of HIV-1 infection with early antiretroviral therapy. N Engl J Med 2011;6:493.

41. Wawer MJ, Gray RH, Sewankambo NK, et al. Rates of HIV1 transmission per coital act, by stage of HIV-1 infection, in Rakai, Uganda. J Infect Dis 2005;191:1403-1409.

42. Donnell D, Baeten JM, Kiarie J, et al. Heterosexual HIV-1 transmission after initiation of antiretroviral therapy: A prospective cohort analysis. Lancet 2010;375:2092-2098.

43. Albert J, Berglund $T$, Gisslén $M$, et al. Risk of HIV transmission from patients on antiretroviral therapy: A position statement from the Public Health Agency of Sweden and the Swedish Reference Group for Antiviral Therapy. Scand J Infect Dis 2914;46:673-677.

44. Rodger A, Cambiano V, Bruun T, Vernazza P, Collins S, et al. for the PARTNER Study Group. HIV transmission risk through condomless sex if the HIV positive partner is on suppressive ART: PARTNER study. The PARTNER Study presented data at CROI 2014 in Boston. Available at: http:// www.chip.dk/PARTNER (Last accessed March 31, 2015).

45. Hasse B, Ledergerber B, Hirschel B, et al. Frequency and determinants of unprotected sex among HIV-infected persons: The Swiss HIV cohort study. Clin Infect Dis 2010;11:1314.

46. Cournil A, Van de Perre P, Cames C, et al. Early infant feeding patterns and HIV-free survival: Findings from the Kesho-Bora Trial (Burkina Faso, Kenya, South Africa). Pediatr Infect Dis J 2015;34:168-174.

47. Fowler MG, Coovadia H, Herron CM, et al. Efficacy and safety of an extended nevirapine regimen in infants of breastfeeding mothers with HIV-1 infection for prevention of HIV-1 transmission (HPTN 046): 18-month results of a randomized, double-blind, placebo-controlled trial. JAIDS 2014;65:366-374.

48. Goffman E. Stigma: Notes on the Management of Spoiled Identity. Penguin Books, Harmondsworth, 1990.

49. Florom-Smith AL, De Santis JP. Exploring the concept of HIV-related stigma. Nurs Forum 2012;47:153-165.

50. Tetri M, Bowleg L, Lloyd L. Pain on top of pain, hurtness on top of hurtness: Social discrimination, psychological well-being, and sexual risk among women living with HIV/ AIDS. J Sex Health 2010;22:205-218.

51. Tomassilli JC, Parsons JT, Golub SA. What's sex got to do with It? The role of sexual affect in the relationship between HIV stigma and mental health. AIDS Behav 2013;17:1770-1774.

52. Muessig KE, Panter AT, Mouw MS, et al. Medicationtaking practices of patients on antiretroviral HIV therapy: Control, power, and intentionality. AIDS Patient Care STDs 2015;11:606-616.

53. Simoni JM, Walters KL, Nero DK. Safer sex among HIV+ women: The role of relationships. Sex Roles 2000;42: 691-708.

54. Bova C, Durante A. Sexual functioning among HIVinfected women. AIDS Patient Care STDs 2003;17:75-83.

55. Massad LS, Farhi MS, Ackatz LE, Sha BE, Benson CA. Sexual behaviors of heterosexual women infected with HIV. J Women's Health 1965;4:681-684.

56. Sarkar NN. Barriers to condom use. Eur J Contracept Reprod Health Care 2008;13:114-122.

57. Berg M, Hotikasalo ML. Pregnancy and diabetes-A hermeneutic phenomenological study of women's experiences. J Psychosom Obstetr Gynecol 2000;21:39-48.

58. Tyer-Viola LA, Lopez RP. Pregnancy with chronic illness. J Obstetr Gynecol Neonatal Nurs 2014;43:25-37.

59. Scarinci EG, Quinn Griffin MT, Grogoriu A, Fitzpatrick JJ. Spiritual well-being and spiritual practices in HIV-infected women: A preliminary study. J Assoc Nurses AIDS Care 2009;20:69-76.

60. House JS, Umberson D, Landis KR. Structures and processes of social support. Ann Rev Sociol 1998;14:293-318.

61. Bury M. Chronic illness as biographical disruption. Sociol Health Illness 1982;4:167.

62. O'Neal CAS. The development of the normalization assessment measure [Ph.D.]. Vanderbilt University, Ann Arbor, 2007.

63. Knafl KA, Deatrick JA. How families manage chronic conditions: An analysis of the concept of normalization. Res Nurs Health 1986;9:215-222.

64. Polit DF, Beck CT. Essentials of Nursing Research: Appraising Evidence for Nursing Practice. Vol. 7 [update]. Wolters Kluwer Health/Lippincott Williams \& Wilkins, Philadelphia, PA, 2010.

65. Wagner AC, Ivanova EL, Hart TA, Loutfy MR. Examining the Traits-Desires- Intentions-Behavior (TDIB) model for fertility planning in women living with HIV in Ontario, Canada. AIDS Patient Care STDs 2014;28:595-601.

66. Finocchario-Kessler S, Mabachi M, Dariotis JK, Anderson J, Goggin K, Sweat M. "We Weren't Using Condoms Because We Were Trying to Conceive'": The need for reproductive counseling for HIV-positive women in clinical care. AIDS Patient Care STDs 2012;26:700-707.

67. Moneyham L, Seals B, Demi A, Sowell R, Cohen L, Guillory J. Experiences of disclosure in women infected with HIV. Health Care Women Intl 1996;17:209.

Address correspondence to: Ms. Ewa Carlsson-Lalloo

Institute of Health and Care Sciences, Box 457 University of Gothenburg 40530 Gothenburg Sweden

E-mail: ewa.carlsson.lalloo@gu.se 